\title{
Reflexões sobre a expansão da UFS no período 2004-2012
}

\author{
Reflection about UFS expansion from 2004 to 2012 \\ Josué Modesto dos Passos Subrinho \\ Departametno de Economia, Universidade Federal de Sergipe, 49100-00, São Cristóvão-SE, Brasil \\ passos@ufs.br \\ (Artigo convidado para a edição comemorativa dos 10 anos da Scientia Plena)
}

\begin{abstract}
Este artigo traz reflexões sobre a expansão da Universidade Federal de Sergipe durante os meus dois mandatos frente a reitoria, de 2004 a 2012.

Palavras-chave: expansão universitária, indicadores de desempenho, REUNI
\end{abstract}

This article presents reflections about the Federal University of Sergipe from 2004 to 2012.

Keywords: university expasion, performance indicators, REUNI

\section{INTRODUÇÃO}

Em nítido contraste com a década de 1980 e primeira metade da década de 1990, os anos entre 2004 e 2012 apresentaram expansão significativa nos principais indicadores de desempenho e porte da Universidade Federal de Sergipe acompanhada de mudanças estruturais na própria instituição. Essas mudanças foram fortemente impulsionadas por uma política nacional de expansão e reestruturação das Instituições Federais de Ensino Superior (REUNI), mas não decorreram da aplicação automática dos dispositivos contidos na política nacional, visto que, pelo menos no caso da UFS, havia uma estratégia anterior de expansão tão ambiciosa quanto a induzida pela política nacional que pressupunha outros mecanismos de incentivos e parcerias delineados na segunda metade da década de 1990 e primeiros anos do novo século. A formalização de uma política nacional de expansão e reestruturação das Instituições Federais de Ensino Superior, por um lado abriu uma senda expansionista, possivelmente com menores custos internos, porém com resistências locais e inspiração política de âmbito nacional.

O nosso propósito será, de um lado apresentar os dados comprobatórios da expansão e mudanças estruturais experimentadas pela UFS no período citado, de outro lado delinear a estratégia política para a aprovação, no âmbito local, das ações expansionistas, bem como das resistências e dificuldades encontradas e, finalmente, a título de conclusão, discutir algumas críticas que o processo de expansão sofreu.

\section{ANTECEDENTES}

Talvez para alguns membros da comunidade universitária brasileira, especialmente em seu segmento público, não tenha ficado claros os mecanismos de governança de uma universidade federal. Muito mais provavelmente ele é estranho para os egressos ou membros de instituições privadas. Considero importante destacar, em linhas gerais, os principais contornos da governança, sem entrar em detalhes de cada Universidade.

Um dos aspectos do regime autoritário de 1964 foi a interferência nas universidades. A aposentadoria compulsória de professores não afinados com os valores ideológicos do regime, a expulsão de lideranças estudantis contestadoras e, finalmente, o filtro ideológico exercido pelas Assessorias de Segurança e Informação, vinculadas ao sistema de segurança do regime, por vezes com a conivência das autoridades acadêmicas, trouxeram para o âmbito da universidade as discussões sobre sua autonomia e escolha de dirigentes, a começar pelo reitor, independentemente das preferências políticas das autoridades. Grosso modo, até então, vigia um mecanismo de seleção de candidatos que permitia amplo poder discricionário aos dirigentes políticos. Para escolha do 
reitor, antes do fim do mandato um conselho universitário, tipicamente representando os dirigentes das faculdades, agregando alguma representação dos docentes mais qualificados e ou antigos, a exemplo dos catedráticos, e pequena representação estudantil elegia uma lista sêxtupla de candidatos a reitor, em escrutínios sucessivos. Cada escrutínio era exitoso se um candidato tivesse o voto da maioria dos conselheiros. A lista sêxtupla era então remetida ao Ministro da Educação que certamente ouvia o governador do Estado antes da nomeação do reitor. O processo não era tão hermético quanto o conclave dos cardeais para a eleição do novo papa, mas tinha algo do mistério, para o grande público, informado por analistas que distinguiam os candidatos com chances dos que apenas ornamentariam seus currículos com a presença na lista sêxtupla, podendo almejar, quem sabe, alguma assessoria ou um cargo de direção de livre nomeação do reitor.

Em meados da década de 1980, como parte de um processo de desgaste do regime autoritário e aproveitando os espaços políticos gerados pela abertura lenta, gradual e segura formulada por dirigentes do próprio regime político, um modelo de consulta ampla à comunidade universitária foi se consolidando. Neste, os possíveis candidatos se inscreviam para uma "eleição" organizada pelos organismos representativos da comunidade, Associação dos Docentes, Sindicato dos TécnicosAdministrativos e Diretório Central dos Estudantes. Como a legislação não havia sido alterada, mantendo-se o mecanismo da lista sêxtupla, a citada "eleição" só teria efeitos práticos se um acordo político fosse feito por todos os potenciais candidatos que se comprometeriam a: 1) não apresentar seu nome aos membros do conselho universitário sem passar pelo crivo da "eleição" na comunidade, 2) não apresentar seu nome aos membros do conselho universitário se o seu nome não fosse o mais votado na consulta à comunidade, 3) o candidato escolhido na "eleição" comunitária apresentaria os nomes que completariam a lista sêxtupla antes da consulta à comunidade ou após, mas, em qualquer caso, estes não aceitariam sua nomeação, sendo portanto esperado que declinassem do possível convite para exercer o cargo de reitor. Em boa parte das universidades federais e em outras que seguiram este modelo, com algumas variações, a consulta a comunidade é paritária, ou seja, o conjunto dos votos dos discentes tem o peso de $1 / 3$, bem como o conjunto dos votos dos docentes representa $1 / 3$ e finalmente o conjunto dos votos dos técnicos-administrativos, outro $1 / 3$.

O modelo acima descrito depende fundamentalmente de um forte consenso na comunidade universitária, visto que todo o processo de consulta se dá à margem da lei, especialmente quando ela foi alterada no Governo Fernando Henrique Cardoso que transformou a lista sêxtupla em lista tríplice, em escrutínio único e uni-nominal [1]. Ou seja, ampliou-se a possibilidade de que candidaturas minoritárias se apresentassem ao Conselho Universitário, com chances de compor a lista e, talvez, de serem indicadas. Nesta mesma reforma, se restringiu a candidatura ao cargo de reitor aos docentes portadores do título de doutor ou ocupantes dos dois últimos níveis da carreira docente e explicitou-se o caráter consultivo da "eleição" comunitária e a possibilidade de a mesma ser regulamentada pelo Conselho Universitário. Para este caso, na consulta dever-se-ia observar a mesma ponderação da participação de docentes nos diversos órgãos colegiados, no mínimo $70 \%$ do total dos votos.

Na UFS a primeira consulta à comunidade para escolha do reitor foi realizada em 1984, organizada pelas entidades representativas dos três segmentos da comunidade universitária. Dado o pioneirismo, ainda não havia a prática de acordo tácito entre os concorrentes para que apenas o mais votado encabeçasse e organizasse a lista sêxtupla a ser referendada pelo Colegiado Eleitoral Especial, previsto no estatuto da UFS. Houve uma profusão de candidaturas e um grupo em torno do ex-reitor Aloísio de Campos formou uma chapa com a pretensão de monopolizar as alternativas que seriam apresentadas ao citado colegiado. Dois candidatos não integrantes do grupo vinculado ao professor Aloísio de Campos terminaram entre os seis mais votados na consulta a comunidade: Murilo Andrade Macedo, professor do curso de Economia, e Eduardo Conde Garcia, professor e pesquisador da área de Fisiologia, vinculada ao ciclo básico dos cursos do Centro de Ciências Biológicas e da Saúde.

O Colegiado Eleitoral Especial referendou a lista da comunidade e o Ministério da Educação indicou o professor Eduardo Conde Garcia para o cargo de reitor da UFS. A partir de então, sucederam-se as consultas à comunidade, sempre com o referendo do Colegiado Eleitoral aos resultados obtidos na comunidade e a indicação pelo Ministro do primeiro colocado e a composição 
da lista com nomes integrantes do grupo liderado pelo candidato a reitor mais votado na consulta comunitária.

Portanto, pelo menos no caso da UFS desde 1988, o decisivo para um candidato a reitor é obter a maioria dos votos na consulta paritária à comunidade universitária. Dado o resultado, o Colegiado Eleitoral formaliza uma lista composta por membros do grupo político-acadêmico liderado pelo candidato a reitor e a interferência das autoridades federais e ou estaduais é pequena, talvez irrelevante. Alguém poderia perguntar se esse sistema não seria totalmente disfuncional tendo em vista as políticas nacionais de educação superior, ciência e tecnologia que supostamente devem em boa parte ser executadas pelas universidades.

$\mathrm{Na}$ realidade, uma série de mecanismos de controle e incentivos foram paralelamente desenvolvidos pelo governo federal para garantir sua influência política na execução das citadas políticas pelas universidades. Ao lado da autonomia da comunidade na seleção dos dirigentes, tendo como ápice o reitor, um maior controle das ações administrativas, condicionando, por exemplo, a liberação de vagas para contratação de docentes e de funcionários, ou parte do orçamento de investimento e custeio à parâmetros de desempenho crescentemente mensurados e acompanhados pelo Ministério da Educação, terminaram induzindo fortemente as administrações universitárias a observar as prioridades de cada governo para melhor obter recursos para a respectiva universidade. De forma aparentemente paradoxal, os próprios movimentos sindicais dos docentes e funcionários administrativos ao conquistarem carreiras únicas nacionais facilitaram a tarefa de padronização dos orçamentos e controles exercidos pelo MEC e, agregando-se mais recentemente, o papel dos organismos de controles interno e externo das contas e de gestão pública.

O primeiro e decisivo passo para a eleição de reitor é, portanto, a conquista da maioria dos votos dos segmentos da comunidade universitária. Um programa tem de ser apresentado pelos candidatos, em sintonia com as aspirações e exorcizando os temores desses segmentos. Os professores e técnicos majoritariamente defendiam um fortalecimento do caráter estatal da universidade, tendo em vista as ações ou tentativas de ações administrativas dos governos dos presidentes Fernando Collor e Fernando Henrique Cardozo visando a relativização da estabilidade no emprego, mudanças nas regras de aposentadoria pública, maior flexibilidade e agilidade administrativa, demandada pela proposta de reforma administrativa do Governo Fernando Henrique Cardoso, com as propostas de criação de entes públicos não estatais, especialmente para os setores de educação, cultura, ciência, tecnologia, saúde e assistência social. Os estudantes temiam principalmente a possibilidade sempre aventada de suprimir ou relativizar a gratuidade do ensino superior através da cobrança de mensalidades para algumas categorias de estudantes, ou através de formas de compensação ao Estado dos gastos despendidos em sua formação e reivindicavam a expansão de programas assistenciais, a exemplo de restaurantes e moradias subsidiados. Por fim, todos queriam dirigentes que por sua profunda e exclusiva vinculação à Universidade dessem maior confiabilidade a essas promessas de campanha.

Em 2004 foi eleita na consulta à comunidade a chapa 100\% UFS liderada por Josué Modesto dos Passos Subrinho e Angelo Roberto Antoniolli. A chapa foi caracterizada como continuísta, já que Josué era vice-reitor em segundo período da gestão liderada pelo Reitor José Fernandes de Lima e concorreu com duas chapas consideradas oposicionistas. Podemos afirmar que tal caracterização elidia algumas ambiguidades. Enquanto os situacionistas poderiam ser associados às políticas de restrição de investimentos e controle rígido na reposição de pessoal docente e técnico, além de políticas salariais contestadas por recorrentes movimentos grevistas, visto ocuparem cargos de confiança do Ministério da Educação, tal imputação era repelida pelos supostos situacionistas que se apresentavam mais como representantes da comunidade acadêmica do que como detentores de cargo de confiança do governo federal e, recorrentemente manifestavam oposição às políticas de contenção de gastos das universidades públicas. As cobranças das chapas oposicionistas ficaram centradas no desempenho administrativo local, cotejando as supostas falhas, negligências ou incompetências da administração e clamando pela necessidade de mudanças, especialmente no grupo que geria a universidade.

Uma das chapas oposicionistas manifestava, surpreendentemente, uma simpatia pela implantação de uma universidade estadual, em Sergipe, sugerindo que seria papel da UFS capitanear um processo de constituição desta nova universidade levando os situacionistas a afirmar que tal proposta subordinava o futuro da UFS ao governo estadual e levantava suspeitas acerca dos 
interesses envolvidos. A outra chapa oposicionista parecia mais afeita a uma cooperação com o setor privado de educação superior, embora as afirmações dos situacionistas estivessem lastreadas mais em ilações do que em fatos irrefutáveis.

Podemos afirmar que, mesmo que muitos dos membros de nossa chapa e, provavelmente, a maioria dos apoiadores não tivessem lido o manifesto dos pioneiros da Educação Nova [2], de 1932, redigido por Fernando Azevedo, Anísio Teixeira e outros, suas ideias, parafraseando o economista John Maynard Keynes, estavam orientando muitas das opiniões de homens e mulheres pragmáticos que imaginavam tê-las colhido diretamente de suas ações, e não da tradução do que liam em vulgatas. Não precisamos aqui fazer uma genealogia das ideias remetendo as discussões do pensamento iluminista e de suas manifestações na revolução francesa do século XVIII que ao definir a autonomia do cidadão como uma moeda de duas faces, a liberdade e a capacidade, erigiam a educação pública universal como o meio para a formação do cidadão da república, isento dos preconceitos da religião, dos costumes tradicionais e dos privilégios. Enfim, um homem formado pela razão, pelas luzes da ciência e capaz de exercer seus direitos à liberdade. Voltamos a insistir, neste contexto o monopólio estatal da educação, suprimindo a hegemonia da Igreja, era tida como parte integrante da formação da república.

Em 16 de novembro de 2004, "eleito" pela comunidade e referendado pelo Colegiado Eleitoral Especial, após a nomeação tomamos posse, em Brasília, perante o então Ministro da Educação, Tarso Genro, do cargo de reitor da UFS. Além do discurso de praxe, apresentamos ao Ministro um ambicioso plano de expansão da Universidade Federal de Sergipe, o qual foi recebido e encaminhado para análise dos organismos técnicos do ministério.

Iniciamos então um périplo de apresentações do Plano de Expansão tanto para os organismos internos da UFS quanto para os diversos órgãos públicos e entidades da sociedade civil.

Passada mais de uma década do evento aqui mencionado, mesmo os observadores mais atentos podem ser confundidos com as brumas que o tempo lança sobre os fatos, diluindo-os em sua sequência, realçando alguns ou suprimindo outros em nossa memória. Acredito ser pertinente recorrer aos registros para oferecer uma interpretação, ao meu julgamento, mais aderente aos fatos.

Para entendermos a amplitude e ambição contidas no Plano de Expansão da UFS, de 2004, precisamos recuar um pouco na trajetória de nossa instituição e, também, mencionarmos as concepções acerca da educação e, mais especificamente, do ensino superior que permeavam muitos de nós a justificar um projeto que, temos de reconhecer, continha uma grande dose de voluntarismo em parte suprida pelas condições excepcionais geradas pouco tempo depois, mas que não eram nada evidentes no momento de sua concepção.

No Brasil, as ideias contidas no Manifesto dos Pioneiros da Educação Nova [2], de 1932, tinham sido revalorizadas especialmente no declínio do regime autoritário instaurado em 1964. A Constituição de 1988, as discussões sobre uma nova Lei de Diretrizes e Bases da Educação Nacional [3], afinal editada em 1996, recolocaram na ordem do dia a implementação de um Sistema Nacional de Educação, sistema que deveria ser universal, no sentido de contemplar toda a população em idade escolar, ou ofertar educação aos adultos ainda não escolarizados, assegurando um padrão nacional de qualidade, e, finalmente, de ser público, garantindo a todos uma formação cidadã. Como conciliar objetivos tão ambiciosos com uma trajetória que, ao final do século XX, ainda convivia com o analfabetismo de adultos e com a chegada de novas gerações que não acessavam à educação básica e com percentuais ínfimos de acesso ao ensino superior, mesmo para os padrões latino-americanos, para não falar dos países mais desenvolvidos. Ou, dito de outra forma, quais eram os principais obstáculos para a concretização das metas implícitas no Sistema Nacional de Educação, imaginado pelos pioneiros da educação nova? Em geral este tema não era objeto de respostas sistemáticas, especialmente no campo dos educadores, mas uma resposta política implícita ou explícita era: falta vontade política para alcançar os objetivos há tanto tempo fixados.

Outra razão para a apresentação de um programa de expansão desafiador era a percepção de que a UFS crescentemente perdia importância relativa no ensino superior sergipano, o que para alguns poderia parecer natural, funcional, mas, para os tributários das ideias dos pioneiros da educação nova, era uma situação a ser revertida.

Como se sabe, o ensino superior, em Sergipe, teve início em 1950 com as Faculdades Estaduais de Química e de Economia, em seguida a Faculdade de Direito, a Faculdade Católica de Filosofia, 
a Escola de Serviço Social e, finalmente, a Faculdade de Medicina. Todas essas faculdades foram incorporadas pelo decreto-lei de 28 de fevereiro de 1967 [4], assinado pelo Presidente da República, Castelo Branco, a então criada Fundação Universidade Federal de Sergipe, a qual foi instalada em 15 de maio de 1968, sendo esta consagrada como data fundadora da Universidade Federal de Sergipe. Até 1972 não existia ensino superior em Sergipe que não fosse de responsabilidade da UFS. A situação monopolista seria quebrada em 1972 e 1975 com a autorização de faculdades ligadas a estabelecimentos privados locais, anteriormente voltados exclusivamente para outros níveis de ensino. A curiosa reivindicação de instituições de ensino superior sergipanas de uma origem cronologicamente anterior a UFS é surpreendente, visto que todos os estabelecimentos de ensino superior sergipanos foram incorporados a UFS, mas tal pretensão pode estar estribada nos anos de protagonismo que o ensino superior privado teve entre nós, e esta pequena disputa simbólica pode ter sido facilitada por nossa negligência em testemunhar enobrecimentos genealógicos, que, como diria o historiador Evaldo Cabral de Melo, pode ter vários usos, abusos e surpresas.

Em 2004, ano da apresentação de nosso Plano de Expansão da UFS, a situação já era bem diferente da hegemonia que a UFS gozara em Sergipe [5]. Podemos tomar o ano de 1999 como um marco importante. Nesse, segundo os dados do Instituto Nacional de Estudos e Pesquisas Educacionais, o total de matrículas estava quase que igualmente distribuída entre a UFS, então única instituição pública de ensino superior, com 8.880 alunos matriculados, e as instituições privadas, com 8.820 alunos matriculados, já em 2004, a situação mudara completamente, de um total de 31.032 alunos matriculados no ensino superior, 11.175 , ou seja, $36 \%$, eram vinculados à UFS e os restantes 64\%, ou seja, 19.857 alunos estavam em instituições privadas. Não apenas estávamos perdendo inexoravelmente peso na quantidade de alunos matriculados, mas, o que era mais grave, tínhamos perdido a capacidade de iniciativa, de inovação em diversas áreas do ensino superior. Estatisticamente, tínhamos muito alunos no interior de Sergipe, visto que nosso principal Campus está localizado em São Cristóvão. De fato, eram estudantes que majoritariamente residiam em Aracaju. As instituições privadas de ensino superior chegavam a diversas cidades do interior. Longe estava o tempo em que elas se contentavam em calcular quantos candidatos não eram atendidos pela oferta de vagas da UFS e ofertavam vagas nos mesmos cursos da universidade. Na estratégia de mercado dos dirigentes privados já se contabilizava quantos candidatos viriam de outros estados e quais áreas de conhecimento não eram atendidas pela UFS. Assim sendo, cursos como jornalismo, farmácia, fisioterapia, medicina veterinária, engenharia elétrica, engenharia mecânica, arquitetura e outros só seriam oferecidos pela UFS depois que similares tivessem sido criados na rede privada. Outro campo onde estávamos atrasados era na utilização de metodologias de ensino à distância, já amplamente ofertada por instituições privadas quando a UFS se iniciou nesta área.

Portanto, para nós, em 2004, se impunha uma tarefa árdua. Diagnosticar as razões da perda de dinamismo relativo da UFS e propor um plano ambicioso que resgatasse o protagonismo da Universidade Pública.

Uma saída fácil e defendida por muitos era simplesmente denunciar o sucateamento da educação e os supostos interesses do Banco Mundial e de outros organismos internacionais na supressão do ensino superior público. Não obstante fosse fato de que os volumes de recursos destinados ao ensino superior federal não tinham mais correspondência com os valores investidos pelo regime militar, quando foram construídos 21 campi universitários e modernizadas as universidades federais e agências de fomento do ensino superior e da pesquisa científica e tecnológica, o fato é que no quadro geral de escassez alguns programas federais e iniciativas de universidades deram bons resultados, alguns dos quais beneficiaram a UFS e outros não.

Ou seja, era possível, e já havia sido praticado na UFS e em outras Universidades, em situações adversas, ter bom desempenho. De forma similar, as condições favoráveis nem sempre eram bem aproveitadas em cada universidade, ou na UFS, em particular.

No caso da UFS podemos exemplificar dois casos de bom aproveitamento num ambiente em geral restritivo. Primeiro: a abertura dos cursos de graduação em Arte-Educação, Jornalismo e Engenharia Agronômica no final de gestão do Reitor Clodoaldo Alencar, não obstante as condições adversas de financiamento e precárias quanto à disponibilização de vagas para docentes e técnicos. Neste período imperava no MEC os primeiros estudos sobre custos das universidades federais. Os 
dirigentes da UFS perceberam, nesse momento, que antes de ser uma ameaça tais estudos eram uma oportunidade, uma vez que tínhamos custos menores que a média do sistema, podendo, portanto, reivindicar recursos adicionais, o que implicitamente estava se fazendo com a ampliação da oferta de cursos.

Na gestão do reitor Luiz Hermínio de Aguiar Oliveira (1992-1996) se procurou novamente saídas na adversidade. A criação da Fundação de Apoio à Pesquisa e Extensão de Sergipe (FAPESE) com o intuito de captar recursos públicos e privados, a conquista de um quadro próprio, porém insuficiente, de pessoal para o Hospital Universitário e, finalmente, o Projeto de Qualificação Docente, exemplificam esta saída pelo crescimento institucional.

Como exemplos de não aproveitamento de oportunidades, tínhamos pelo menos a decisão, tomada no final da gestão do reitor Aloísio de Campos, de não dar eficácia a um dispositivo normativo que exigia dos auxiliares de ensino a conclusão do curso de mestrado para ingresso na carreira docente. Pelo contrário, foi aprovada uma nova carreira que privilegiava o tempo de serviço em detrimento da titulação, desestimulando fortemente os professores a buscar os centros nacionais e estrangeiros para obtenção dos seus títulos de mestre e doutor. Posteriormente a implicação seria imensa. O crescimento permitido às universidades federais nas décadas de 1980 e 1990 estava fortemente vinculado aos cursos de pós-graduação que na UFS, em decorrência do pequeno número de professores titulados, demorou a ocorrer.

Outro exemplo, por razões puramente internas, foi o não aproveitamento de vagas docentes disponibilizadas para as universidades federais que se dispusessem a criar cursos noturnos. Os preconceitos, por vezes inconfessados, quantos aos cursos noturnos, continuam tendo ampla vigência em nossas universidades. Para alguns colegas, esses cursos parecem ser apanágios das instituições privadas.

Resumidamente, tínhamos convicções sobre o papel da universidade pública, clareza de que boa parte do fazer ou não fazer é de nossa exclusiva responsabilidade, a legitimação de um mandato recém conferido pela comunidade e confirmado pelos dirigentes do Ministério da Educação e, mais, a ousadia dos jovens. Então por que não propor algo ousado, no limite da temeridade?

\section{O PLANO DE EXPANSÃO DA UFS (2005-2008)}

Os objetivos fixados pelo Plano de Expansão da UFS 2005/2008 foram os seguintes:

1. Ampliar a oferta dos cursos de graduação, diurnos e noturnos, oportunizando a inclusão social duradoura e a diminuição da desigualdade social e regional, ao formar profissionais, professores e pesquisadores.

2. Diversificar a oferta do ensino de graduação com a implantação de cursos em áreas pouco contempladas na oferta atual, como Engenharias e Artes.

3. Institucionalizar as atividades de ensino, pesquisa e extensão no interior do Estado tornando permanentes os Polos Regionais de Estância, Itabaiana, Lagarto, Nossa Senhora da Glória e Propriá.

4. Consolidar os programas de pós-graduação existentes.

5. Criar novos programas de pós-graduação

6. Estimular experiências de educação à distância.

7. Ampliar o programa de bolsas acadêmicas a fim de assegurar a permanência de estudantes carentes por meio de programas de monitoria e prestação de serviços comunitários.

8. Intensificar as relações com o setor produtivo do Estado, por meio de transferências de tecnologias de processo, produto e gestão.

9. Disseminar práticas de tecnologia social para encontrar soluções para os problemas identificados pelas comunidades carentes do Estado.

10. Concluir o Polo de Novas Tecnologias, iniciado em 2000, especificamente com a implantação das unidades de Microeletrônica e Biotecnologia.

11. Implantar o Centro de Vivências, com espaços para manifestações culturais, reuniões, encontros, assembleias, debates e prestação de serviços, a exemplo de correios, reprografia, livrarias, entre outros.

12. Instalar laboratórios para atender aos novos cursos. 
13. Transformar o Hospital Universitário (HU) em hospital de alta complexidade, assegurando a sua autogestão e viabilizando o seu crescimento, assim como a ampliação dos seus serviços.

14. Ampliar o quadro docente efetivo de 583 para 1.358 professores, a fim de suprir a defasagem atual e preparar a instituição para os desafios propostos.

15. Ampliar o quadro de servidores técnicos e administrativos em 300 funcionários.

16. Implantar programa de valorização de recursos humanos, incluindo a capacitação dos servidores técnico-administrativos, geradora de estímulo e compromisso com as atividades funcionais e de uma mais acurada compreensão sobre o papel da instituição.

Além desses objetivos, o plano fixava estratégias e metas, ou seja, comprometia-se com a entrega de resultados que certamente seriam cobrados no devido tempo.

Antes de ser uma premonição do REUNI [6], estabelecido pelo decreto N. 6.096 de 24 de abril de 2007, o Plano de Expansão da UFS decorria da vivência e aprendizado da comunidade acerca das relações da Universidade com o seu mantenedor, o governo federal, e de uma retomada do impulso desenvolvimentista no qual o papel atribuído à universidade pública é central.

Se ainda não havia uma indução clara do governo federal acerca da expansão das universidades federais, em que bases se apoiavam as estratégias e metas anunciadas pelo Plano de Expansão da UFS, além da simples vontade?

Embora não estejam registradas no citado documento, as fontes implícitas para o impulso expansionista da UFS eram:

a) O aprofundamento dos mecanismos de controle e avaliação do MEC para orientar a distribuição dos recursos orçamentários e as autorizações para a contratação de pessoal docente e técnico. Esses mecanismos foram institucionalizados na gestão do Ministro Paulo Renato de Souza e mantidos ao menos até a gestão do Ministro Cristóvão Buarque, o primeiro do Governo do Presidente Lula. Havia uma ampla expectativa de premiação da UFS, com o recebimento de recursos adicionais, visto fazer mais com menos, tendo em vista a média do sistema federal.

b) O aporte de recursos orçamentários extras a partir da ação da bancada parlamentar federal do Estado de Sergipe através de emendas às Leis Orçamentárias Anuais, permitindo o incremento do orçamento a que a UFS fazia jus segundo os modelos do Ministério da Educação.

c) O aprofundamento de relações com empresas e instituições públicas ou privadas, identificando projetos de interesse comum que permitissem a ampliação das atividades de ensino, pesquisa e extensão da Universidade. Alguns exemplos notórios em outras universidades, ou experiências bem-sucedidas na própria UFS deveriam ser generalizadas. Um exemplo foi a construção do Centro de Vivência, financiado em boa parte, pelo Banco do Brasil que tem sua agência bancária como âncora do empreendimento, a construção do Fórum de Assistência Judiciária no interior do Campus e, finalmente, mas sem esgotar a lista, a construção do Núcleo Regional de Competência Científica e Tecnológica em Petróleo, Gas e Biocombustíveis, financiado por recursos da Agência Nacional de Petróleo e Petrobras.

d) O desenvolvimento da Fundação de Apoio à Pesquisa e Extensão de Sergipe, (FAPESE) como interface a viabilizar prestações de serviços da Universidades, desde os educacionais (Projetos de Qualificação Docente, Projeto de Qualificação de Recursos Humanos para Reforma Agrária) de extensão e de pesquisa.

e) Relacionamento de alto nível com os governos estadual e municipais visando a prestação de serviços e a obtenção de apoio estratégico para a expansão da Universidade.

f) Estabelecimento de um novo patamar de relacionamento com a sociedade civil, especialmente com ex-alunos, estimulando desde o trabalho voluntário até possíveis doações para constituição de novos fundos para investimento e custeios pontuais, a exemplo da assistência estudantil. Uma nova entidade, a Sociedade dos Amigos e exalunos da UFS (SOUFS) foi criada com este objetivo.

Algumas das fontes de financiamento da expansão e estratégias políticas de legitimação da expansão foram desenvolvidas conforme previsto. Logo percebemos, porém, como é difícil mudar 
padrões de relacionamento dentro da comunidade acadêmica e desta com a sociedade. Havia todo um esforço que resultava em escassos ou inexistentes resultados para, por exemplo, abrir espaços para o trabalho voluntário ou para doações. Da mesma forma, os relacionamentos com empresas e instituições públicas ou privadas, mesmo quando exitosos produziam atritos tanto na comunidade acadêmica quanto choques com as outras instituições. Sabe-se que estes ajustamentos, feitos por diversas universidades em diversos países é uma das fontes inspiradoras de incontáveis ensaios acerca da crise da universidade.

Estávamos no meio dessas reformas, com avanços, recuos, derrotas e negociações quando a fonte generosíssima do REUNI obrigou as universidades federais a se redefinirem em favor de uma expansão rápida e permeada de turbulências, sendo a parte mais visível as invasões dos Conselhos Universitários por grupos minoritários que se opuseram a expansão, mesmo na UFS onde ela já estava em andamento e os recursos extras eram providenciais e oferecidos praticamente sem ônus, visto que este já havia sido contratado pela própria Universidade.

\section{RESULTADOS}

Em novembro de 2012, pudemos apresentar no relatório de gestão correspondente a dois mandatos consecutivos uma síntese das mudanças havidas na UFS nesse período [5]. Para os observadores menos afeitos ao mundo universitário, o que mais chamava a atenção era a transformação nos prédios que faziam confundir os que conviveram na Cidade Universitária Prof. José Aloísio de Campos até o início dos anos 2000, tantos eram os novos edifícios, tantas mudanças nas fachadas tradicionais de alguns.

Mas muito além, do aspecto físico, a universidade se transformara em outros aspectos, demarcamos os que julgamos mais importantes.

O primeiro foi a transformação da Universidade Federal de Sergipe numa universidade multi campi. O processo de interiorização começado com a implantação do Campus Universitário Professor Alberto Carvalho, em Itabaiana, em 2006, teve prosseguimento com a implantação do Campus de Laranjeiras e, finalmente, com o Campus Universitário Professor Antônio Garcia Filho, em Lagarto.

O segundo foi a instituição do Núcleo Regional de Competência Científica e Tecnológica em Petróleo, Gás e Biocombustíveis, NUPEG, em parceria com a PETROBRAS e Agência Nacional de Petróleo (ANP) pela capacidade potencial de vincular parte das áreas de conhecimento desenvolvidas na UFS, em parcerias para a superação dos desafios científicos e tecnológicos que a produção de petróleo, gás e biocombustíveis representam para o Brasil e para Sergipe. A confirmação da existência de reservas de hidrocarbonetos em águas profundas do litoral sergipano, reitera este setor como crucial para o futuro desenvolvimento de Sergipe. A Universidade Federal de Sergipe, que possuía lacunas em importantes áreas do conhecimento para a formação de pessoal e para o desenvolvimento de pesquisas para essa indústria, implantou, simultaneamente, cursos de graduação e pós-graduação que maximizarão o potencial científico e tecnológico desse núcleo.

O terceiro foi a implantação do Centro de Educação Superior à Distância (CESAD) para a Universidade Aberta do Brasil, UAB, fortemente vocacionado para a formação de professores da educação básica, através de cursos de licenciatura na modalidade educação semipresencial, com a utilização de tecnologias de informação e comunicação. Este centro não apenas permite a inclusão de estudantes que não teriam possibilidades de acesso ao ensino superior convencional, mas também permite a produção de moderno material didático, impactando positivamente, inclusive, a educação superior presencial.

$\mathrm{O}$ quarto foi o direcionamento da Universidade para políticas inclusivas, tendo em vista o histórico de insensibilidade quanto às necessidades de segmentos sociais excluídos do acesso ao ensino superior. Além do já citado CESAD, um conjunto de ações foi desenvolvido em consonância com essa diretriz. Devemos mencionar os esforços para ampliação do número de vagas em cursos de graduação especialmente nas opções de cursos noturnos, mais adequados às necessidades dos estudantes trabalhadores, a própria implantação de campi universitários no interior do Estado, potencializando o acesso de estudantes residentes nos municípios interioranos e, final e especificamente, a adoção do Programa de Ações Afirmativas (PAAF), com reserva de 50\% das 
vagas, em cada curso para os egressos da escola pública e, dentro desta quota, uma sub quota para os auto declarados negros, pardos ou indígenas, com o percentual de $70 \%$. Adicionalmente, reservou-se uma vaga, em cada curso, aos portadores de deficiências. Depois de intensas polêmicas, a Universidade Federal de Sergipe obteve a declaração de constitucionalidade de seu programa pelo Tribunal Federal Regional da $5^{\text {a }}$. Região, com sede em Recife. O Supremo Tribunal Federal declarou a constitucionalidade destas políticas e, finalmente, o Congresso Nacional aprovou lei regulando o acesso às vagas em curso de graduação, nas instituições federais de ensino superior, com formato assemelhado ao adotado pela Universidade Federal de Sergipe.

$\mathrm{O}$ quinto foi a mudança qualitativa permitida pelo grande incremento quantitativo que a Universidade Federal de Sergipe teve, no período 2004-2012, em seus corpos docente e discente. Nesse período, o número de professores efetivos passou de 461 para 1.136. Nos anos seguintes, novas autorizações permitiram a continuidade da expansão do corpo docente. A tendência ao incremento na titulação dos docentes foi acentuada não apenas com a manutenção das políticas de incentivos vigentes, desde a década de 1980, como também pela indução de contratação de novos docentes, com a maior titulação possível, nas diversas áreas do conhecimento. Assim sendo, o número de docentes com o título de doutor passou de 165, em 2004, para 728, em 2012, ou seja, um crescimento de $341 \%$, elevando, no mesmo período, a participação dos docentes com o título de doutor, de $35,7 \%$ para $64 \%$.

Quanto ao corpo discente, ultrapassamos 31.000 alunos, em 2012, dos quais 25.456, na graduação presencial, e 5.562 na graduação semipresencial, frente aos 10.217 alunos de graduação, em 2004, ou seja, o crescimento nas matrículas de graduação foi de $216 \%$. Mais rápido ainda foi o crescimento na matrícula de alunos na pós-graduação stricto sensu, mestrados e doutorados, passando de 357 para 1.908, no mesmo período, isto é, um crescimento de $434 \%$.

Outro aspecto importante nas mudanças quantitativas e qualitativas ocorridas no mencionado período foi a supressão de lacunas na oferta de cursos de graduação. Para a formação de professores da educação básica, quase todas as áreas já eram contempladas, sendo a principal crítica a inadequação da oferta em período diurno, por vezes, em turno integral, quando os estudantes demandavam período noturno. Praticamente, todos os cursos de licenciaturas são ofertados no período noturno, ou possuem também uma opção de turno noturno. Foram criados cursos novos, na área de Artes (Música, Teatro e Dança), Engenharias e Tecnologia (Engenharia Mecânica, Engenharia de Materiais, Engenharia de Petróleo, Engenharia Ambiental, Engenharia de Produção, Engenharia Agrícola, Engenharia de Pesca, Engenharia da Computação, Sistemas de Informação e Geologia) na área de Saúde ( Nutrição, Fisioterapia, Fonoaudiologia e Terapia Ocupacional), bem como nas Ciências Sociais Aplicadas (Turismo, Secretariado Executivo, Relações Internacionais e Biblioteconomia).

De certa forma mais intensa que essa impressionante mudança na oferta de cursos de graduação foi a mudança na pós-graduação. De uma oferta de apenas 9 cursos, sendo um doutorado e 8 mestrados, em 2004, passamos para 46 cursos em 2012, ou seja, um crescimento de $411 \%$, dos quais 38 mestrados e 8 doutorados, abrangendo todas as grandes áreas do conhecimento. Esse impressionante crescimento da pós-graduação foi permitido, principalmente, pelo expressivo crescimento no corpo docente titulado, pela maior disponibilidade de recursos das agências federais de fomento à ciência e tecnologia e, em especial, por um funcionamento exemplar da Fundação Estadual de Amparo à Ciência, Tecnologia e Inovação - FAPITEC, e, finalmente, por ações de fomento da própria Universidade Federal de Sergipe.

\section{CONCLUSÃO}

O nosso propósito foi demonstrar, especialmente para as novas gerações que encontraram uma Universidade que retomou a hegemonia em Sergipe, especialmente na capacidade de formatar projetos acadêmicos de qualidade aferida nacionalmente e internacionalmente, que este objetivo foi alcançado em um período relativamente curto e, o que é mais surpreendente, com uma mudança de estratégia tendo em vista a drástica mudança nas condições que envolviam o ambiente universitário brasileiro, muito especificamente as universidades federais. 
O abandono da estratégia anterior, centrada nas condições especificas da UFS e do seu papel no processo de desenvolvimento de Sergipe pela nova de adesão ao Programa REUNI [6] facilitou o atingimento das metas ambiciosas contidas no Plano de Expansão da UFS, permitindo a Universidade, num prazo relativamente curto, interiorizar suas atividades, dar saltos qualitativos com a ampliação dos corpos docente e técnico-administrativos, reconfigurar o perfil socioeconômico de parte dos estudantes com as políticas afirmativas, suprir lacunas na oferta de cursos em praticamente todas as áreas de conhecimento e consolidar-se como centro de pesquisa e pós-graduação.

Por outro lado, se examinarmos os dados da matrícula em cursos de graduação, em 2013, último ano em que dispomos dados do Censo do Ensino Superior, verificaremos um excepcional crescimento nas matrículas, em Sergipe, dos 31.032 estudantes computados em 2004 passamos para 80.702 , no referido ano de 2013 . O curioso é que não obstante o excepcional crescimento da UFS e a transformação do antigo CEFET em Instituto Federal de Sergipe, com a oferta, inclusive, de cursos de graduação, a participação do setor público cresceu discretamente, passando de $36 \%$ para $37 \%$. Ou seja, mesmo num período extraordinário é extremamente difícil a perseguição, no Brasil, do ideal de ensino superior público hegemônico, como imaginavam os pioneiros da escola nova.

Se colocados no panorama nacional, contudo, este percentual de $37 \%$ da matricula em estabelecimentos públicos de ensino superior, é significativo, visto que no Brasil, como um todo, o percentual correspondente, no mesmo ano, foi de $26,4 \%$ e o percentual de matriculados em estabelecimentos de ensino federal foi de $15,6 \%$. Na região Nordeste, no mesmo ano, tivemos praticamente o mesmo percentual de matriculados em estabelecimentos públicos que o alcançado em Sergipe, 36,9\%, com a diferença que este em Sergipe se deu exclusivamente em estabelecimentos federais e na região Nordeste os estabelecimentos federais contemplaram 22,9\% das matrículas sendo o restante distribuído entre estabelecimentos estaduais e municipais.

Acredito, contudo, que a expansão recente da UFS a levou incontestavelmente a uma situação distinta no sistema estadual de ensino superior. Nos Estados Unidos, por exemplo, o sistema tem uma multiplicidade de instituições públicas e privadas, e o termo universidade, a exemplo do que ocorre em outros países, se vulgarizou. Temos universidades corporativas, universidades de sanduíches, de cervejas etc. Mas a ideia e o ideal da universidade continuam sendo pautados pelos estabelecimentos que efetivamente conseguem associar ensino pesquisa, extensão, inovação e internacionalização ao seu fazer acadêmico, e a separação entre os que se dedicam às tarefas complexas e os que se dedicam apenas a ministrar ensino é dado por um teste prático: qual o peso dos cursos de doutorado em sua oferta de cursos, visto que neste nível é preciso um investimento intenso, especialmente em recursos humanos, para formular novos temas de pesquisa e formar novos pesquisadores com autonomia intelectual.

Acho que todo o percurso que fizemos valeu a pena por termos simultaneamente gerado novas condições para assegurar nossa vanguarda na qualidade acadêmica, na pertinência social e na relevância política.

As condições para a expansão do ensino superior público mudaram drasticamente recentemente. A principal mudança é certamente o forte estresse fiscal que se abate sobre todas as esferas do Estado brasileiro, agravado recentemente com o aprofundamento da crise econômica e com uma nova dinâmica em que a crise política e econômica se retroalimentam. Se aprendemos algo com nossa história, aprendemos que sempre é possível tentar e, eventualmente, ter êxito nas saídas criativas; não tentar é contratar o fracasso. Cada geração tem o dever de analisar as condições para a permanência da universidade no centro do processo civilizatório e fazer o melhor possível nestas condições que foram dadas ao invés de lamentar a ausência de um mundo que proveria todas as condições ideais para os nobres exercícios acadêmicos.

\section{REFERÊNCIAS BIBLIOGRÁFICAS}

1. BRASIL. Lei $\mathrm{n}^{\circ}$ 9.192, de 21 de dezembro de 1995. Altera dispositivos da Lei $\mathrm{n}^{\circ}$ 5.540, de 28 de novembro de 1968, que regulamentam o processo de escolha dos dirigentes universitários. 
Disponível em http://www.planalto.gov.br/ccivil_03/LEIS/L9192.htm. Acesso: 18 de março de 2016.

2. Fernando de Azevedo et al. Manifestos dos pioneiros da Educação Nova (1932) e dos educadores (1959). Recife: Fundação Joaquim Nabuco, Editora Massangana, 2010.

3. BRASIL. Lei ${ }^{\circ}$ 9.394, de 20 de dezembro de 1996. Estabelece as diretrizes e bases da educação nacional. Disponível em http://www.planalto.gov.br/ccivil_03/leis/L9394.htm. Acesso: 18 de março de 2016.

4. BRASIL. Decreto-Lei $n^{\circ}$ 269, de 28 de fevereiro de 1967. Autoriza o Poder Executivo a instituir a Fundação Universidade Federal de Sergipe e dá outras providências. Disponível em http://www.planalto.gov.br/ccivil_03/decreto-lei/1965-1988/Del0269.htm. Acesso: 18 de março de 2016.

5. Universidade Federal de Sergipe. Relatório de Gestão UFS 2004-2012. http://oficiais.ufs.br/sites/default/files/21/relatorio_ufs__web2.pdf. Acesso: 18 de março de 2016.

6. BRASIL. Decreto $n^{\circ}$ 6.096, de 24 de abril de 2007. Institui o Programa de Apoio a Planos de Reestruturação e Expansão das Universidades Federais - REUNI. Disponível em http://www.planalto.gov.br/ccivil_03/_ato2007-2010/2007/decreto/d6096.htm. Acesso: 18 de março de 2016. 